\title{
Study of Spectrum of Histopathological Findings in Breast Carcinomas, after Neoadjuvant Chemotherapy
}

\author{
Authors \\ Dr Renuka Gahine ${ }^{1}$, Dr Shashikala Kosam ${ }^{2}$, Dr Sandhya Verma ${ }^{3 *}$ \\ ${ }^{1}$ Director Professor \& Head Department of Pathology, Pt.J.N.M. Medical College Raipur (C.G.) \\ ${ }^{2}$ Assistant Professor, Department of Pathology, Pt.J.N.M. Medical College Raipur (C.G.) \\ ${ }^{3}$ Post Graduate Student Department of Pathology, Pt.J.N.M. Medical College Raipur (C.G.) \\ *Corresponding Author \\ Dr Sandhya Verma
}

Address- R-11, Street no. 3, Dubey colony, Mowa Raipur Pin Code: 492007, India Email: sandhyaverma231990@gmail.com, Mobile no.- 9755227113

Abstract
Background: Neoadjuvant chemotherapy is currently established as a standard therapeutic approach
for patients with large $(>2 \mathrm{~cm})$ and locally advanced breast cancer. The histopathological evaluation of
tumor response is the gold standard.
Methods: Histopathologic examination was done in 44 MRM specimen received in the department of
pathology over a period of 1 year from August 2017 to July 2018.
Results: $44 / 44$ cases are of female breast. Mean age of patient is 50 years. Mean size before CT was
$56.14 \mathrm{~cm}^{2}$ and after CT was $29.40 \mathrm{~cm}^{2}$. In the present study $18 \%$ cases show complete pathologic
response and $84 \%$ cases show incomplete response.
Conclusion: Characteristic pattern of changes observed after histopathological examination of tumor
bed are cellular fibrous tissue, reactive lymphocytic infiltration, haemosiderin laden macrophages, areas
of coagulative necrosis, stromal hyalinization, dystrophic calcification.
Keywords: Neoadjuvant chemotherapy, breast carcinoma, pathologic response.

\section{Introduction}

NAT is currently established as a standard therapeutic approach for patients with large $(>2$ $\mathrm{cm})$ and locally advanced breast cancer $^{(1)}$. However, standard guidelines for pathologic evaluation of breast specimens after NAT have not been established ${ }^{(2-7)}$. Assessment of the therapeutic response and measurement of residual disease in the breast and/or axillary lymph node is important because it may predict survival and provide guidelines for further therapy ${ }^{(7,8)}$. This study will discuss spectrum of histologic alterations that can be seen in malignant breast tissue and also demonstrate how to evaluate, sample and measure residual breast cancer in excision specimens including axillary lymph nodes after neoadjuvant chemotherapy.

\section{Aim}

Study of spectrum of histopathological findings in breast carcinomas after neoadjuvant chemotherapy. 


\section{Objectives}

1) To study the gross and microscopic changes induced after NAT in breast carcinoma.

2) To observe the pathologic response to treatment.

\section{Material and Method}

Total 44 cases for prospective study were selected from all post chemotherapy MRM specimen received in the the department of pathology over a period of 1 year from August 2017 to July 2018. Patients received 4-6 cycles of paclitaxel based chemotherapy (adriamycin, cyclophosphamide, and paclitaxel) and underwent modified radical mastectomy with axillary lymph node dissection (MRM).A detailed history of the patient noted as per proforma with special reference to age, sex, occupation, residence, presenting complaint with their duration, past history of surgery, chemotherapy and radiotherapy. Tissue received for histopathological examination was fixed in $10 \%$ formalin. After adequate fixation specimen were subjected to thorough gross examination. Multiple bits from the tissue were taken after appropriate gross inspection and margins designation. Background tissues at multiple points were also assessed and lymph nodes (if present) were resected and submitted for processing in order to assess tumor spread. Tissues processed in automated tissue processor. Paraffin blocks were made and 5-6 micron sections were cut with the help of microtome and slides were stained with Harris Haematoxyline and Eosin stain (H \& E). The post chemotherapeutic changes were studied from the MRM specimens. The histological grading was done by Bloom Richardson grading system. The histopathological evidence of the chemotherapeutic response was graded from the H\&E sections. Pathological complete response was defined as the disappearance of all the tumor or DCIS in breast with no invasive carcinoma and negative lymph nodes.

\section{Results}

A total of 44 patients belonging to age group of 21- 70 years were included in the study. Mean age of patient was 50 years. All patients were female. Majority of them were premenopausal (55\%) and $45 \%$ were postmenopausal. All patients received CEF drug regimen for chemotherapy. Majority of the patients $(35 \%)$ received 6 cycles of chemotherapy followed by 4 cycles $(11.4 \%)$.All patients had unilateral breast lump. Central quandrant was the most common location (38.63\%) followed by upper inner $(22.72 \%)$ quadrant. Majority of patients had fixed breast lesion (95.5\%). Mean size before CT was 56.14 $\mathrm{cm}^{2}$ and after CT was $29.40 \mathrm{~cm}^{2}$. Size after chemotherapy was found to be significantly reduced compared to that before chemotherapy $(\mathrm{P}$ value $-<0.0001)$.Significant difference was noted after chemotherapy indicating significant conversion of firm and hard lesions to fleshy lesions. (Pearson chi-square value-5.500 ${ }^{\mathrm{a}}$, Continuity correction $^{\mathrm{b}}$ value-3.819, Likelihood ratio-6.067). Out of 44 cases majority of cases $79.5 \%$ diagnosed as IDC followed by Suspicious of malignancy $(6.8 \%)$, adenocarcinoma (4.5\%), DCIS $\quad(2.3 \%), \quad$ ILC(2.3\%), Metastatic adenocarcinoma (2.3\%), Sclerosing adenosis/ infiltrating carcinoma (2.3\%) before chemotherapy. Majority of cases $(75 \%)$ diagnosed as IDC followed by no residual tumor(15.9\%), DCIS (6.8\%), Adenocarcinoma(2.27\%) after chemotherapy.7 patients $(15.9 \%)$ responded completely with no malignant cells left after extensive sampling. In 4 cases $(9.09 \%)$ only microscopic foci of tumor cells present, 4 patients (9.09\%) had diffuse microscopic carcinoma, that is, no macroscopic tumour was visible but at histologic examination diffuse infiltration of tumor cells noted. 29 patients (65.9\%) had macroscopic tumor. Maximum no. of $\mathrm{LN}$ mets $<5(75 \%)$ and least no. of cases of $>15 \mathrm{LNs}$ mets $(2.3 \%)$. Most of the cases $(84.1 \%)$ margins were free from tumor. Out of 44 cases 42 cases $(95.5 \%)$ shows fibrosis,36 cases $(81.8 \%)$ shows necosis, 43 cases(97.7\%) shows chronic 


\section{JMSCR Vol||07||Issue||01||Page 611-616||January}

inflammatory cell infiltrate, 7 cases shows DCIS component (15.9\%),12 cases(27.3\%) shows vascular invasion,9 cases(20.5\%) shows lymphatic invasion,6 cases(13.6\%) shows calcification and 21 cases(47.7\%) showing haemorrhage. So the most common change observed is inflammatory host response and most common inflammatory host response is lymphocytic,others included mixed inflammation, plasmacytic,histiocytic type.

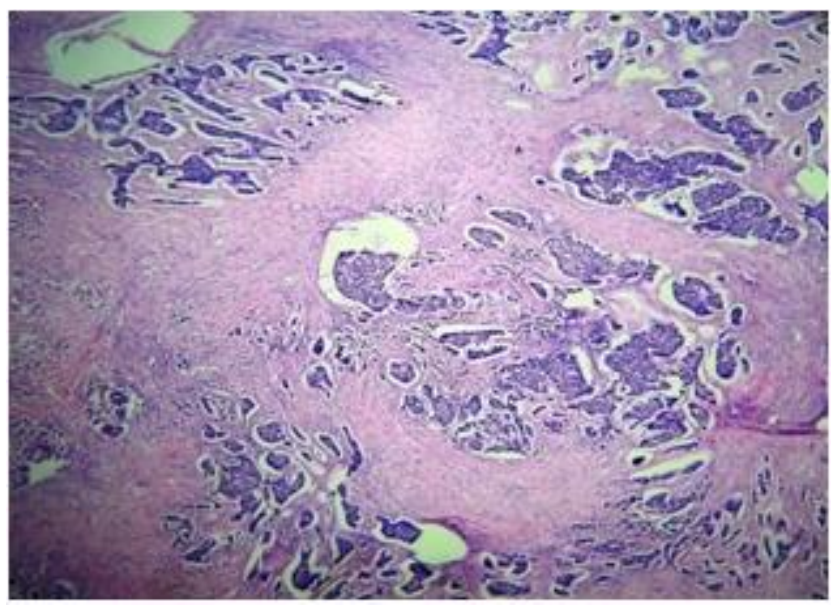

Photomicrograph of Residual tumor after NCT, showing tumor cells in clusters, which tend to shrink away from the stroma( H\&E,10x)

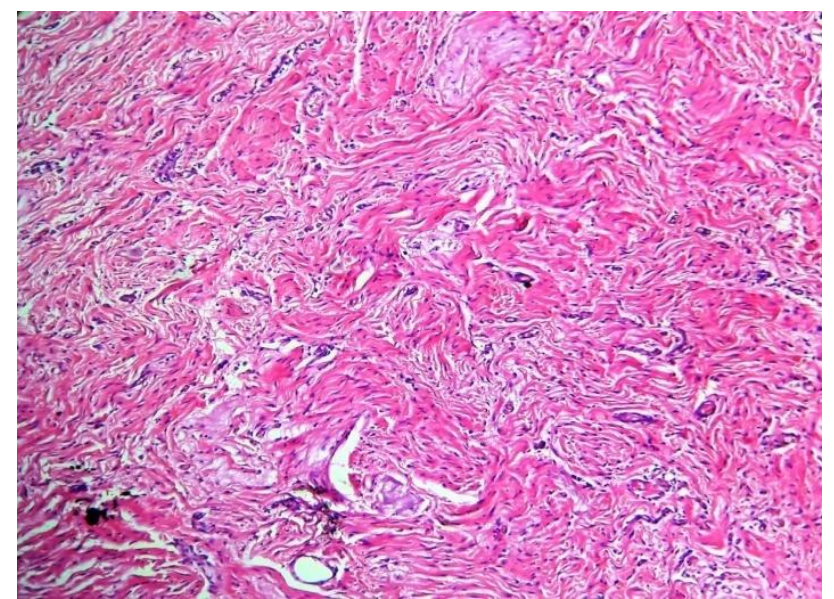

Photomicrograph of Tumor bed after NAT showing extensive area of fibrosis along with inflammatory cells in case of complete response to therapy. (H\&E,10x)

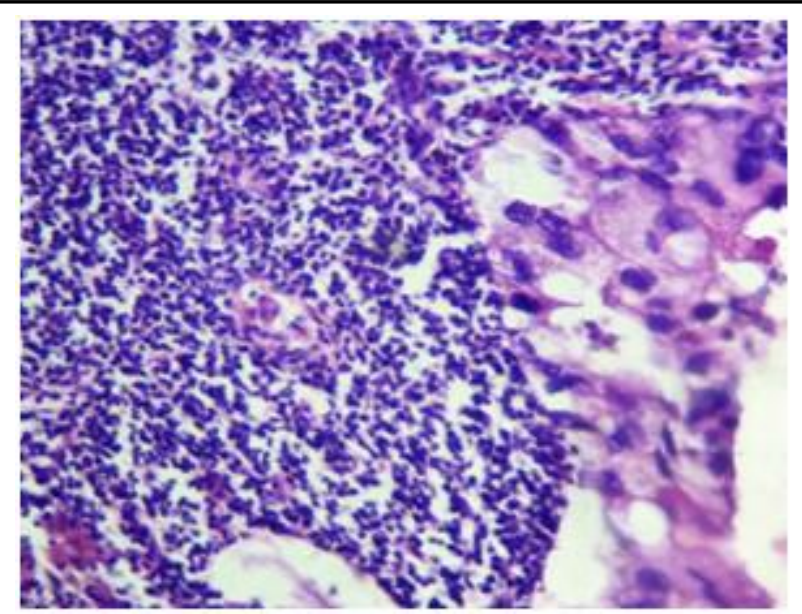

Photomicrograph of Residual tumor after NCT, showing dense lymphocytic infiltrate, closely abutting the tumor cells. ( $\mathrm{H} \& \mathrm{E}, 40 \mathrm{x}$ )

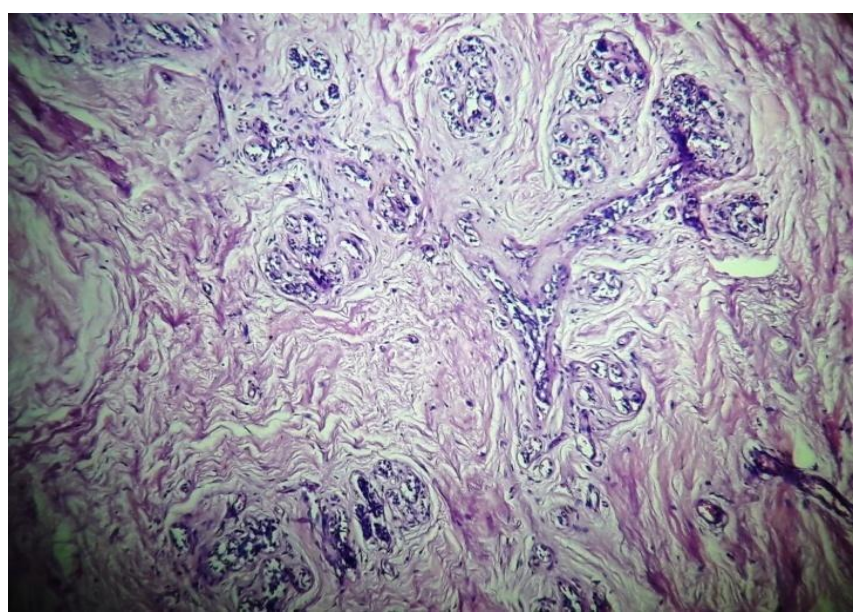

Photomicrograph of The normal breast terminal ductal lobular unit (TDLU) shows atrophy and diminished acini after neoadjuvant chemotherapy. (H\&E, 10x)

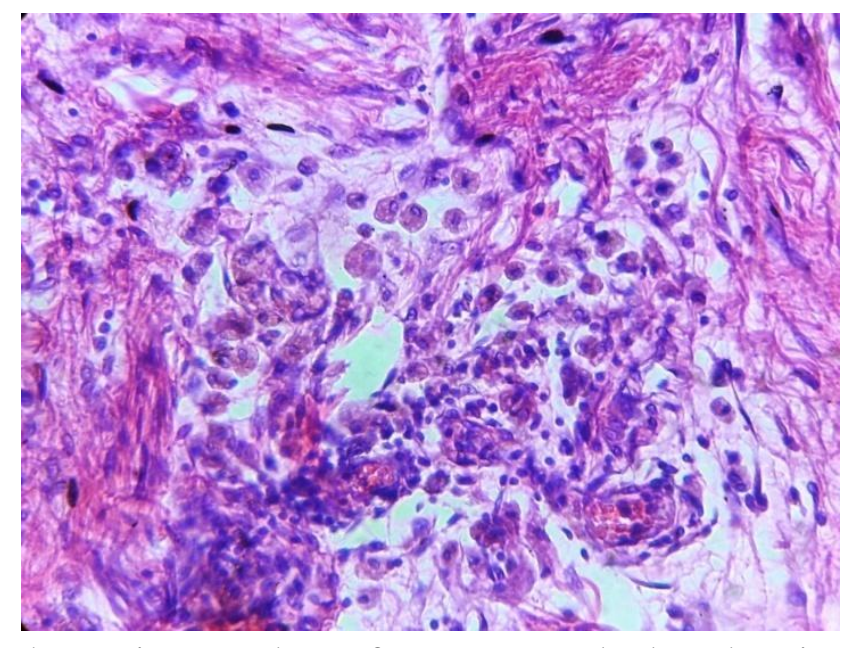

Photomicrograph of Tumor bed showing hemosiderin-laden macrophages and lymphocytes (H\&E,40x) 
Table 1: Characteristics of tumor after chemotherapy

\begin{tabular}{|l|c|c|}
\hline Characteristics of tumor & Frequency & Percentage \\
\hline No residual tumor after CT & 7 & 15.90 \\
\hline $\begin{array}{l}\text { Minimal microscopic tumor after } \\
\text { CT }\end{array}$ & 4 & 9.09 \\
\hline $\begin{array}{l}\text { Diffuse Microscopic tumor after } \\
\text { CT }\end{array}$ & 4 & 9.09 \\
\hline Macroscopic tumors after CT & 29 & 65.90 \\
\hline
\end{tabular}

Table no. 1 shows characteristics of tumor after chemotherapy .7 patients $(15.9 \%)$ responded completely with no malignant cells left after extensive sampling. In 4 cases $(9.09 \%)$ only microscopic foci of tumor cells present, 4 patients (9.09\%) had diffuse microscopic carcinoma, that is ,no macroscopic tumour was visible but at histologic examination diffuse infiltration of tumor cells noted. 29 patients (65.9\%) had macroscopic tumor.

Table 2: Characteristics of lesion after chemotherapy

\begin{tabular}{|l|c|c|}
\hline $\begin{array}{l}\text { Characteristics of } \\
\text { lesion }\end{array}$ & $\begin{array}{c}\text { No. of } \\
\text { subjects }\end{array}$ & Percentage \\
\hline Firbrosis & 42 & 95.5 \\
\hline Necrosis & 36 & 81.8 \\
\hline $\begin{array}{l}\text { Inflammatory } \\
\text { infiltrate }\end{array}$ & 43 & 97.7 \\
\hline Hemorrhage & 21 & 47.7 \\
\hline Calcification & 6 & 13.6 \\
\hline DCIS component & 7 & 15.9 \\
\hline Lymphatic invasion & 9 & 20.5 \\
\hline Vascular invasion & 12 & 27.3 \\
\hline Total & 44 & 100 \\
\hline
\end{tabular}

Table no.2 shows Characteristics of lesion after chemotherapy, 42 cases( $95.5 \%$ ) shows fibrosis,36 cases $(81.8 \%)$ shows necosis, 43 cases $(97.7 \%)$ shows chronic inflammatory cell infiltrate, 7 cases shows DCIS component(15.9\%),12 cases(27.3\%) shows vascular invasion,9 $\operatorname{cases}(20.5 \%)$ shows lymphatic invasion,6 cases(13.6\%) shows calcification and 21 cases(47.7\%) showing haemorrhage. So the most common change observed is inflammatory host response and most common inflammatory host response is lymphocytic, others included mixed inflammation, plasmacytic, histiocytic type.

\section{Discussion}

The role of the pathologist is to assess the impact of chemotherapy on the primary breast cancer and/or its metastases to the axillary lymph nodes ${ }^{(86)}$.In the present study peak age group is 41-50 years constituting 36\% of all patients with age range of 21-70 years. Mean age of presentation of lesion is 50 years, which is similar to study done by Demaria $S$ et al $(2001)^{(9)}$, Shushu Wang et al(2013) ${ }^{(10)}$ i.e.50.6 and 48.99 years respectively, All patients are female which is similar to study done by Chakrabarti $\mathrm{S}$ et al $(2018)^{(11)}$, Ramana kumari P et al (2015) ${ }^{(12)}$, Vasudevan D et al(2015) ${ }^{(13)}$, Shushu Wang et al $(2013)^{(10)}$.

In the present study, out of 44 patients $24(55 \%)$ are premenopausal and 20(45\%) are postmenopausal which is similar to study done by Narendra $\mathrm{H}$ et al (2018) ${ }^{(14)}$. Maximum no. of premenopausal patients $734(77 \%)$ reported by $\mathrm{S}$ Baulies et al (2016) ${ }^{(15)}$.

In the present study $33(75 \%)$ cases reported as IDC, 3 cases reported as DCIS and 1 case as adenoarcinoma after NAT while 7 cases responded completely with no malignant cells left after extensive sampling. Vasudevan $\mathrm{D}$ et al $2015^{(13)}$ reported $79.2 \%$ cases as IDC, $2.1 \%$ as ILC.S Baulies et al $2016^{(15)}$ reported $76 \%$ cases as IDC ,7\% as ILC and $3 \%$ other cases. . Siregar KB et al $2017^{(16)}$ reported $96 \%$ cases as IDC ,4 \% as ILC. Hamy-Petit AS et al $2016^{(17)}$ reported $94 \%$ cases as IDC and $2 \%$ other cases. Narendra $\mathrm{H}$ et al $2018^{(14)}$ reported $96 \%$ cases as IDC,4\% as ILC.

In the present study $18 \%$ cases show complete pathologic response and $84 \%$ cases show incomplete response. Majority of cases show incomplete response which may be due to advance stage. Hamy-Petit AS et al(2016) ${ }^{(17)}$ reported $39 \%$ cases of complete pathologic response and $60.9 \%$ cases of incomplete response. Jung YY et al(2016) (18) reported $46.2 \%$ cases of complete pathologic response and $53.8 \%$ cases of incomplete response. Vasudevan D et al(2015) ${ }^{(13)}$ reported $27.1 \%$ cases of complete pathologic response and $72.9 \%$ cases of incomplete response. Pu RT et al(2005) ${ }^{(19)}$ 
reported $9 \%$ cases of complete pathologic response and $83.63 \%$ cases of incomplete response.

In the present study 42 cases shows fibrosis, 36 cases shows necosis, 43 cases shows chronic inflammatory cell infiltrate, 7 cases shows DCIS component,11 cases shows vascular invasion,9 cases shows lymphatic invasion, 6 cases shows calcification and 21 cases showing haemorrhage. The characteristic pattern of changes in lymph nodes with metastasis consisted of fibrotic areas and when present scattered foci of tumor cells in between and occasionally with iron loaded macrophages. 23 cases showed lymphatic metastasis and in 6 cases margins were involved. Similar observations are reported in other studies. Ramana Kumari $\mathrm{P}$ et $\mathrm{al}^{(12)}$ observed spectrum of changes in the tumor bed is coagulative necrosis, hyalinisation, dystrophic calcification and intense mononuclear inflammatory cell collections, cytoplasmic vacuolization and bizarre nuclei. The changes observed in the lymph node metastases are hyaline stromal scars, necrosis and aggregates of histiocytes, without any viable tumor cells. In lymph nodes with partial response, isolated and clusters of tumor cells surrounded by hyaline stromal fibrosis is observed. Chakrabarti $\mathrm{S}$ et al (11) observed frequent morphological changes in histological examination were decreased cellularity, chronic inflammatory cells (61.5\%), fibrosis $(64.1 \%)$ and necrosis $(30.8 \%)$. Honkoop $\mathrm{AH}$ et $\mathrm{al}^{(20)}$ observed a characteristic pattern of relatively cellular fibrous tissue with lymphocytic infiltrate, iron loaded macrophages, and, when present, scattered foci of tumor cells in between.

\section{Conclusion}

From the above study, we conclude that histopathological examination of the tumor bed is the gold standard for assessing the chemotherapeutic tumor response. Characteristic pattern of changes observed after histopathological examination of tumor bed are cellular fibrous tissue, reactive lymphocytic infiltration, haemosiderin laden macrophages, areas of coagulative necrosis,

stromal hyalinization, dystrophic calcification.

\section{References}

1. Thompson AM, Moulder-Thompson SL. Neoadjuvant treatment of breast cancer. Ann Oncol 2012; 23 Suppl 10: x231-6.

2. Mamounas EP, Anderson SJ, Dignam JJ, et al. Predictors of locoregional recurrence after neoadjuvant chemotherapy: results from combined analysis of National Surgical Adjuvant Breast and Bowel Project B-18 and B-27. J Clin Oncol 2012; 30: 3960-6.

3. Carey LA, Metzger R, Dees EC,Collichio F, Sartor CI, Ollila DW, Klauber-DeMore N, Halle J, Sawyer L, Moore DT,Graham ML (2005). American Joint Committee on Cancer tumor-node-metastasis stage after neoadjuvant chemotherapy and breast cancer outcome. J Natl Cancer Inst 97: 1137-42

4. Ogston KN, Miller ID, Payne S et al. A new histological grading system to assess response of breast cancers to primary chemotherapy: prognostic significance and survival. Breast 2003;12:320-327

5. Abrial SC, Penault-Llorca F, Delva R, et al. High prognostic significance of residual disease after neoadjuvant chemotherapy: a retrospective study in 710 patients with operable breast cancer. Breast Cancer Res Treat 2005; 94: 255-63.

6. Pinder SE, Provenzano E, Earl H, Ellis IO. Laboratory handling and histology reporting of breast specimens from patients who have received neoadjuvant chemotherapy. Histopathology 2007; 50: 409-17.

7. Symmans WF, Peintinger F, Hatzis $C$ et al. Measurement of residual breast cancer burden to predict survival after neoadjuvant chemotherapy. J Clin Oncol 2007;25:44144422

8. Penault-Llorca F, Abrial C, Raoelfils I et al. Comparison of the prognostic significance 
of Chevallier and Sataloff's pathologic classifications after neoadjuvant chemotherapy of operable breast cancer. Hum Pathol 2008;39:1221-1228

9. Demaria S, Volm MD, Shapiro RL, Yee HT, Oratz R, Formenti SC, et al. Development of tumor-infiltrating lymphocytes in breast cancer after neoadjuvant paclitaxel chemotherapy. Clin Cancer Res 2001;7:3025-30.

10. Wang et al.: Shrink pattern of breast cancer after neoadjuvant chemotherapy and its correlation with clinical pathological factors. World Journal of Surgical Oncology 2013 11:166

11. Chakrabarti S, Mandal PK, Chowdhury AR, Das S.et al Consequence of neo-adjuvant chemotherapy on morphology of breast carcinoma: A systematic evaluation. Indian J Cancer 2016;53:29-33.

12. Ramana Kumari P, Sivarama Krishna TV, NagaKishore MG.et al Cytomorphological changes in breast carcinomas, after neoadjuvant chemotherapy: a study of twenty cases. Int J Res Med Sci 2015;3:3326-30

13. Dhanya Vasudevan,P. S. Jayalakshmy, Suresh Kumar, and Siji Mathew Assessment of Pathological Response of Breast Carcinoma in Modified Radical Mastectomy Specimens after Neoadjuvant Chemotherapy International Journal of Breast Cancer Volume 2015, Article ID 536145, 8 pages

14. Narendra H, Thomas J, Ray S, Fernandes DJ et al An analysis of response to neo-adjuvant chemotherapy in patients with locally advanced breast cancer with emphasis on pathological complete response, Indian Journal of Cancer | October-December 2014 | Volume 51 | Issue 4

15. S Baulies, L Belin, P Mallon, C Senechal, J-Y Pierga , P Cottu , M-P Sablin , X Sastre, B Asselain , R Rouzier and F Reyal et al,
Time-varying effect and long-term survival analysis in breast cancer patients treated with neoadjuvant chemotherapy British Journal of Cancer (2015) 113, 30-36.

16. Siregar KB, Pane J, Siburian R. Et alCorrelation between Tumor-Infiltrating Lymphocytes and Pathological Response in Locally Advanced Breast Cancer Patients Who Received Neoadjuvant Chemotherapy in H. Adam Malik General Hospital. Case Rep Oncol. 2017 Aug 4;10 (2):699-705. doi: 10.1159/000477799. eCollection 2017 May-Aug)

17. Anne-Sophie Hamy-Petit, Lisa Belin , He' le' ne Bonsang-Kitzis, Caroline Paquet, Jean-Yves Pierga, Florence Lerebours, Paul Cottu , Roman Rouzier, Alexia Savignoni , Marick Lae and Fabien Reyal et al Pathological complete response and prognosis after neoadjuvant chemotherapy for HER2-positive breast cancers before and after trastuzumab era: results from a real-life cohort British Journal of Cancer (2016) 114, 44-52

18. Jung YY, Hyun CL, Jin MS, Park IA, Chung YR, Shim B, Lee KH, Ryu HS. et al Histomorphological Factors Predicting the Response to Neoadjuvant Chemotherapy in Triple-Negative Breast Cancer. J Breast Cancer. 2016 Sep; 19(3):261-267. Epub 2016 Sep 23.

19. Pu RT, Schott AF, Sturtz DE, Griffith KA, Kleer CG.et al Pathologic features of breast cancer associated with complete response to neoadjuvant chemotherapy: importance of tumor necrosis Am J Surg Pathol. 2005 Mar;29(3):354-8.

20. Honkop AH, Pinedo HM, Dejong JS, et al. Effects of chemotherapy on pathological characteristics of locally advanced breast cancer. Am J Clin Pathol 1997;107:211218. 